\title{
The Implications of Academic Dishonesty in Undergraduate Engineering on Professional Ethical Behavior
}

\author{
D.D. Carpenter ${ }^{1}$, T.S. Harding ${ }^{2}$, C.J. Finelli ${ }^{3}$ \\ 1 Lawrence Technological University; Civil Engineering Department, 21000 W. Ten Mile Road, \\ Southfield, MI 48075; PH (248) 204-2549; carpenter@ltu.edu \\ 2 Kettering University; Industrial and Manufacturing Engineering, $1700 \mathrm{~W}$. Third Avenue, Flint \\ MI, 48504; PH (810) 762-9811; tharding@kettering.edu \\ 3 University of Michigan; Center for Research on Learning and Teaching, 4117 Engineering \\ Research Building I, Ann Arbor, MI 48109; PH (734) 763-9601; cfinelli@umich.edu
}

\begin{abstract}
Student academic dishonesty, commonly referred to as cheating, has become a serious problem at institutions of higher education. This is particularly true of engineering students who, according to previous research, are among the most likely to cheat in college. In addition, research on college students in all fields has indicated that such behavior is more common among students who participate in academic dishonesty at the high school level and that it is correlated with other deviant or unethical behaviors, such as petty theft and lying. If, in fact, such correlations do exist, one might hypothesize that there is also a relationship between academic dishonesty in college and deviant or unethical behavior in professional practice. Placing this relationship in the context of higher levels of academic dishonesty among engineering students only increases the seriousness of the problem for engineering educators, professionals, corporations, and society. To investigate this concern, the authors have undertaken two research projects. The first project focused on the Perceptions and Attitudes toward Cheating among Engineering Students (PACES1). The goal of the research was to develop a better understanding of what students and faculty perceive as cheating and to use this knowledge to help instructors and institutions increase the level of academic integrity. The second project examined the correlation between academic dishonesty and unethical behavior with a majority of the students in the sample having worked for a considerable period of time during their college years. This provided a unique opportunity to study the connection between academic dishonesty and professional behavior within the same sample of individuals. This paper will discuss some of the implications of academic dishonesty on professional ethical behavior and provide an overview of the two investigations conducted by the authors.
\end{abstract}

\section{Implications}

Academic dishonesty is distressingly prevalent on college campuses throughout the United States; with upwards of $80 \%$ of undergraduates reporting that they have cheated at least once during college with engineering students being reported among the highest offenders (Bowers, 1964; Brown, 1996; McCabe \& Drinan, 1999; McCabe \& Trevino, 1997; Brown \& Emmett, 2001; Spiller \& Crown, 1995). As an indication of the difference by major, McCabe (1997) collected data from 1,946 undergraduates at 16 institutions and found that $82 \%$ of engineering students self report engaging in any type of cheating compared to $91 \%$ of business students, $73 \%$ of social sciences students, and $71 \%$ of natural sciences students.

Peer-reviewed proceedings of the 2006 World Environmental and Water Resources Congress, Omaha, NB. 
The issue of widespread cheating is a concern for society at large, and this issue is beginning to receive national media attention. For example, there have been widely-publicized cheating scandals at high profile universities such as Georgia Technological University and the U.S. Air Force Academy, and an ABC Primetime Special entitled "Cheaters amok. A crisis in America's schools: How it's done and why it's happening" was aired on national television in April 2004 (ABC, 2004). The Primetime special examined high school and college cheating and presented the same alarming statistics described previously. The special also showed interviews of students who easily rationalized and justified their cheating. Students cited corporate scandals, such as those at Enron and Arthur Anderson, as well as political scandals and judicial findings as reasons they cheat. Students also indicated that, rather than being enrolled in college to learn, they were there to "get ahead in life." These high profile and somewhat sensationalistic news stories may erode the general populations faith in the higher educational system for producing ethical and competent graduates. In addition, student and faculty morale, the reputation of the institution, and public confidence in higher education are all damaged by rampant cheating (Whitley \& KeithSpiegel, 2002).

The consequence of unethical behavior is immediately apparent at the collegiate level. Students who cheat misrepresent their abilities and may receive an advantage over their peers. Acts of academic dishonesty also undermine the validity of measures of student learning. However, the longer-term consequences are cause for even greater concern. A student who has managed to cheat his way through college not only presents a false impression of himself to a future employer, but may also have such a poor sense of moral obligation and responsibility that he cannot be expected to act ethically as a professional engineer. As an indication of this concern, college cheating has been linked to other unethical behaviors. Research has shown that students who cheat in college are more likely to cheat in graduate and professional schooling (Baldwin, Daugherty, Rowley, \& Schwartz, 1996), to engage in unethical work-place behavior (Harding et al, 2003a, 2003b; Hilbert, 1985; Nonis \& Swift, 2001; Ogilby, 1995; Sims, 1993; ToddMancillas, 1987), and to cheat on income taxes (Fass, 1990). In this case much more than the integrity of the academic process is at stake because engineers (more often than their business counterparts) are responsible for the health and physical welfare of the public.

\section{PACES-1 Project}

The authors designed the PACES-1 Survey to understand perceptions and attitudes of engineering undergraduate students about cheating, and to use this information to identify factors that influence a student's decision on whether to cheat or not. Much of the published literature about academic dishonesty uses large student populations with homogeneous backgrounds to achieve an unbiased sample of student responses. However, these samples are not representative of engineering students. This has lead to a lack of information about what factors might result in the increased cheating among engineers reported earlier. As such, information presented in this section is based upon data collected from a direct-question survey (PACES-1 Survey) designed to identify perceptions and attitudes of engineering undergraduate students about cheating. The survey was developed after an extensive review of literature on the subject (Carpenter et al, 2002a; Harding et al, 2001) and is modeled on the work of several researchers (Cochrane, 1999; McCabe, 1997). The seven-page survey contains 139 questions that are subdivided into seven parts. The survey was completed by 643 undergraduate engineering and pre-engineering undergraduates at eleven institutions in the United States and abroad, including large public universities, small private universities, and community colleges with pre-engineering programs. A total of $81.0 \%$ of respondents were male and $18.8 \%$ female. The mean age was 21.6 years with

Peer-reviewed proceedings of the 2006 World Environmental and Water Resources Congress, Omaha, NB. 
a range of 17 to 48 years of age (however, 89.5\% of the respondents were under 26 years of age). There is good representation of year in college with $22.9 \%$ of respondents being in their first year, $13.7 \%$ in their second year, $24.1 \%$ in their third year, $21.3 \%$ in their fourth year, and $18.7 \%$ being in their fifth or more year of undergraduate instruction. Also, the surveys were administered in courses in a range of engineering disciplines.

Results from the PACES-1 Project

This section presents an overview of the student responses on the survey along with insight towards research questions for the PACES-1 Project: what is student cheating and how often does it occur; why do students cheat; and what methods can be used to reduce or stop cheating? Student responses are documented in tables, which report the valid percentage of each categorical response to a given question. Only some representative results are presented here. Readers interested in a more detailed analysis can refer to several other manuscripts that have been published by the authors (Carpenter et al, 2002a; Carpenter et al, 2002b; Finelli et al, 2003; Passow et al, 2005; Passow et al, 2006).

What is student cheating and how often does it occur?

Before the issue of how often students cheat can be addressed, one must define what constitutes cheating (at least in the students' mind). Therefore, one goal of this study was to determine what this sample of students defines as cheating. To this end, students were given twenty behavioral acts and asked whether they considered each to be "Cheating", "Unethical but not cheating", or "Neither". This provided the students' definition of cheating, which was subsequently used to interpret students' reports of how frequently the engaged in each action as a college student. The results are presented in Table 1 . The first column lists the survey question verbatim, the next three columns list the percentage of students defining each scenario as "Cheating", as "Unethical but not cheating" and as "Neither," and the last three columns indicate how often (in percentage of responses) respondents engaged in the behavior.

Peer-reviewed proceedings of the 2006 World Environmental and Water Resources Congress, Omaha, NB. 
Table 1: Percentage of students defining each category as cheating and frequency of each (highest percentage of each category is bold).

\begin{tabular}{|c|c|c|c|c|c|c|}
\hline & \multicolumn{3}{|c|}{$\begin{array}{l}\text { Attitude Toward } \\
\text { Cheating }\end{array}$} & \multicolumn{3}{|c|}{$\begin{array}{l}\text { Frequency of Cheating } \\
\text { Behavior }\end{array}$} \\
\hline & 骂 & 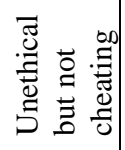 & 氖 & 0 & $1-2$ & $3+$ \\
\hline a) Copying from another student during a test or quiz & 96.4 & 2.3 & 1.1 & 63.3 & 20.2 & 11.5 \\
\hline $\begin{array}{l}\text { b) Permitting another student to look at your answer during a quiz or } \\
\text { exam }\end{array}$ & 73.3 & 23.3 & 3.4 & 53.7 & 25.3 & 15.4 \\
\hline $\begin{array}{l}\text { c) Asking another student about questions on an exam you have not } \\
\text { yet taken }\end{array}$ & 26.7 & 45.6 & 26.6 & 27.2 & 29.9 & 37.5 \\
\hline $\begin{array}{l}\text { d) Delaying taking an exam or turning in a paper later with a false } \\
\text { excuse }\end{array}$ & 24.9 & 65.5 & 8.7 & 68.9 & 19.4 & 6.4 \\
\hline $\begin{array}{l}\text { e) Copying from an unapproved reference sheet during a closed-book } \\
\text { test or quiz }\end{array}$ & 91.6 & 5.8 & 1.9 & 68.1 & 19.0 & 7.3 \\
\hline $\begin{array}{l}\text { f) Claiming to have handed in an assignment or exam when you did } \\
\text { not }\end{array}$ & 61.1 & 33.0 & 4.5 & 86.6 & 4.4 & 1.9 \\
\hline g) Taking an exam for another student & 92.1 & 5.4 & 1.7 & 89.9 & 2.0 & 1.2 \\
\hline $\begin{array}{l}\text { h) Working in groups on assignments when there is no class policy } \\
\text { on group work }\end{array}$ & 6.4 & 20.1 & 72.5 & 14.6 & 19.1 & 59.6 \\
\hline i) Copying an old term paper or lab-report from a previous year & 60.7 & 26.1 & 12.3 & 55.7 & 22.9 & 14.2 \\
\hline j) Studying with other students for a test & 0.6 & 2.2 & 96.3 & 3.7 & 5.3 & 85.1 \\
\hline $\begin{array}{l}\text { k) Copying another student's homework when it is not permitted by } \\
\text { the instructor }\end{array}$ & 72.9 & 22.6 & 3.9 & 37.9 & 31.7 & 24.3 \\
\hline $\begin{array}{l}\text { l) Submitting or copying homework assignments from previous } \\
\text { terms }\end{array}$ & 52.3 & 31.1 & 16.0 & 58.2 & 18.4 & 16.8 \\
\hline $\begin{array}{l}\text { m) Witnessing a case of cheating in a class and not reporting it to the } \\
\text { instructor }\end{array}$ & 9.2 & 59.6 & 30.3 & 41.1 & 26.0 & 27.2 \\
\hline $\begin{array}{l}\text { n) Storing answers to a test in a calculator or Personal Digital } \\
\text { Assistant (PDA) }\end{array}$ & 74.5 & 15.6 & 9.8 & 54.9 & 18.8 & 20.1 \\
\hline o) Paying someone else to take an exam/write a paper for you & 87.1 & 10.7 & 1.6 & 89.1 & 3.4 & 1.1 \\
\hline p) Working in groups on web-based quizzes & 40.7 & 29.4 & 29.1 & 66.4 & 14.8 & 11.8 \\
\hline q) Working in groups on take-home exams & 39.0 & 28.6 & 31.4 & 53.2 & 25.2 & 14.9 \\
\hline
\end{tabular}

Table 1 does present several interesting findings. For example, when considering student responses to questions regarding examinations, $96.4 \%$ of students responded that "copying from Peer-reviewed proceedings of the 2006 World Environmental and Water Resources Congress, Omaha, NB. 
another student during a test or quiz" (item a) was cheating; yet only $73.3 \%$ responded that "permitting someone else to look at your answer during a quiz or exam" (item b) was cheating. Students made a definite distinction between performing the act of copying and permitting others to copy. The number of times a student has engaged in each activity varies accordingly with $31.7 \%$ of students admitting to copying from others at least one time in a typical college term and $40.7 \%$ allowing others to copy. Additionally, only $40.7 \%$ responded that "working in groups on web-based quizzes" (item p) was cheating with 29.1\% stating it is neither cheating nor unethical. Similar rates were reported for "working in groups on take-home exams" (item q). These rates are significantly lower than if the quiz or exam was held in the class. It appears as if the use of out of class examinations change students' opinions on cheating.

Another significant relationship found in Table 1 is the distinction students make between "Cheating" and "Unethical but not cheating." In casual conversations with faculty, the authors have found that most do not make a distinction between something being unethical and cheating. Most faculty hold the belief that if something is unethical, it must be dishonest, and subsequently, must be academically dishonest. However, Table 1 indicates that a large portion of students make a distinction between unethical behavior and cheating.

Why do students cheat?

Trying to determine why students cheat is problematic, as each individual student will decide whether or not to cheat in a given situation based on a variety of factors. However, one way to address this question is to consider common hypotheses of why students cheat including a growing social acceptability, grade competition, and peer pressure. These hypotheses were included in a list of statements about cheating and students responded using a 5-point Likert scale from "Strongly disagree" to "Strongly agree" with the results presented in Table 2.

The student responses to statements regarding these hypotheses are surprising and differ from the authors' expectations. For example, there is some indication that academic dishonesty is becoming a social norm or " necessary part of life." Yet, a majority of students disagreed with the statement "cheating is a necessary part of life" (item e) with only $13.0 \%$ in agreement. Likewise, engineering is commonly considered a highly competitive environment in which students might feel more compelled to cheat to compete with other students. However, only 4.9 $\%$ of students agreed or strongly agreed with the statement "I have to cheat just to get grades good enough to compete with the other students at this school” (item j) and $46.5 \%$ strongly disagreed. Regarding the hypothesis that peer pressure as a reason students cheat, $60.4 \%$ of respondents disagreed or strongly disagreed with the statement "if a good friend asked me to cheat for them, I wouldn't be able to say no" (item l), which suggests limited effects of peer pressure. Another interested result found in Table 2 was that $66.6 \%$ of respondents agreed or strongly agreed with the statement "other students cheat more frequently than I do" (item k), with only $3.6 \%$ in disagreement. Essentially, students are convinced everyone cheats as much if not more than they do. When developing the survey, the authors believed that if students perceive others are cheating more than they are, they are more likely to cheat themselves. However, data from this study does not clearly confirm this belief. For example, nearly half (48.5\%) of respondents disagreed or strongly disagreed with "I would cheat in a class if it seemed everyone else was cheating” (item $\mathrm{m}$ ). Therefore, identifying the role of students' perceptions of their peers' behavior in cheating requires further consideration.

Peer-reviewed proceedings of the 2006 World Environmental and Water Resources Congress, Omaha, NB. 
Table 2: Student opinions on statements about cheating (in percentage of responses with highest percentage of each category in bold).

\begin{tabular}{|c|c|c|c|c|c|}
\hline & 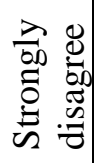 & 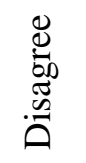 & 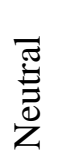 & 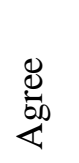 & 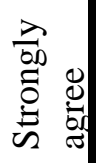 \\
\hline a) Helping someone else cheat is not as bad as cheating myself & 18.4 & 28.8 & 18.2 & 29.2 & 5.1 \\
\hline b) It is my responsibility to prevent cheating & 17.3 & 31.4 & 29.4 & 16.6 & 5.0 \\
\hline c) It is the instructor's responsibility to prevent cheating & 2.5 & 7.0 & 10.9 & 50.1 & 29.2 \\
\hline d) It is the institutions responsibility to prevent cheating & 3.3 & 9.5 & 14.0 & 47.6 & 24.9 \\
\hline e) Cheating is a necessary part of life & 31.4 & 34.4 & 20.5 & 9.0 & 4.0 \\
\hline $\begin{array}{l}\text { f) If I saw another student cheating I would report the student to the } \\
\text { instructor }\end{array}$ & 20.7 & 37.9 & 30.6 & 7.8 & 2.6 \\
\hline g) If I saw another student cheating I would confront the student & 21.9 & 39.7 & 26.1 & 9.5 & 2.2 \\
\hline h) If I saw another student cheating I would do nothing & 3.1 & 13.1 & 31.4 & 37.2 & 14.9 \\
\hline i) I would cheat to avoid getting a poor or failing grade in class & 22.6 & 31.6 & 23.2 & 16.8 & 5.3 \\
\hline $\begin{array}{l}\text { j) I have to cheat just to get grades good enough to compete with other } \\
\text { students at this school }\end{array}$ & 46.5 & 37.6 & 10.3 & 4.0 & 0.9 \\
\hline k) Other students cheat more frequently than I do & 1.4 & 2.2 & 27.5 & 36.7 & 29.9 \\
\hline l) If a good friend asked me to cheat for them, I wouldn't be able to say no & 22.6 & 37.8 & 19.8 & 13.7 & 5.6 \\
\hline m) I would cheat in a class if it seemed that everyone else was cheating & 16.3 & 32.2 & 27.7 & 19.1 & 4.0 \\
\hline n) I would cheat if doing so helped me retain my financial assistance & 17.6 & 29.7 & 25.5 & 21.2 & 5.3 \\
\hline
\end{tabular}

If these reports of anticipated behavior conform to actual attitudes about cheating, it would appear cheating is not becoming a social norm and is perceived as wrong by a significant majority of engineering students. Also, according to these results, engineering students are not motivated to cheat by perceptions of a highly competitive environment or by excessive peer pressure. If many of these common hypotheses for cheating behavior are not at the root of the problem, then what is?

One intriguing possibility when trying to determine why students cheat is to explore their value judgment system. One method student values were assessed in this study was by asking participants to respond to statements designed to address psychological factors about cheating as well as whose responsibility it is to prevent cheating. These statements along with student responses are also presented in Table 2. Overwhelmingly, students believe the responsibility to limit cheating belongs to the instructors and the institution (over $70 \%$ agree or strongly agree)

Peer-reviewed proceedings of the 2006 World Environmental and Water Resources Congress, Omaha, NB. 
and not themselves (only $21.6 \%$ agree or strongly agree to the statement "it is my responsibility to prevent cheating" (item b)). Additionally, a majority of students would not report instances of cheating to an instructor or confront a student they observed cheating, with only $16.2 \%$ of students disagreeing or strongly disagreeing with the statement, "If I saw another student cheating I would do nothing" (item h). However, in Table 1, a majority of students (59.6\%) responded that "Witnessing a case of cheating in a class and not reporting it to the instructor" (item o) was unethical. This is an important finding because it suggests that although a majority of students believe it is unethical to not report other cheaters (59.6\%), yet very few students (16.2\%) predict that they would act on this belief, representing a discrepancy between student beliefs about and compliance with a behavior.

What methods can be used to reduce or stop cheating?

Arguably, the responsibility for reducing cheating lies with both students and academic institutions, and one of the most important components to promoting academic integrity on our campuses is to increase the understanding of what constitutes cheating and increase the communication about academic integrity between students and faculty. As such, another section of the survey to be presented here directly asked the students their opinions about several deterrents to cheating. Because responses were of most interest from students who have or who would consider cheating, students who felt they would never cheat under any circumstances were instructed to skip this section of the survey. Those students who felt they might cheat then replied either "Yes", "No", or "Don't Know" to 23 deterrents that might have prevented them from cheating. Overall, $66.1 \%$ of all respondents completed this part of the survey and their responses are summarized as percentages in Table 3. If only $66.1 \%$ of respondents completed this section, it can be inferred that $33.9 \%$ would never consider cheating under any circumstances. However, this number is inconsistent with results from other parts of the survey. The first part of the survey investigated student definitions of cheating and frequency of occurrence. Student responses in Table 1 indicate that less than $10 \%$ of respondents have never engaged in an act that they defined as either cheating or unethical. This apparent discrepancy (less than 10\% compared to 33.9\%) could be attributed to either students not wanting to complete this section of the survey (the survey instrument was lengthy) or inconsistent student and faculty definitions of cheating.

Peer-reviewed proceedings of the 2006 World Environmental and Water Resources Congress, Omaha, NB. 
Table 3: Student attitudes about actions that might deter cheating (in percentage of responses with highest percentage of each category in bold).

\begin{tabular}{|c|c|c|c|}
\hline & Yes & No & $\begin{array}{l}\text { Don’t } \\
\text { Know }\end{array}$ \\
\hline $\begin{array}{l}\text { a) If the institution had an honor code that clearly described what } \\
\text { constituted cheating and penalties for cheating }\end{array}$ & 40.9 & 29.2 & 29.9 \\
\hline b) If classes were smaller & 43.1 & 28.0 & 28.9 \\
\hline c) If the instructor discussed the institution's penalties for cheating & 40.8 & 33.0 & 26.1 \\
\hline d) If the instructor discussed the penalties for cheating in their course & 43.6 & 26.8 & 29.6 \\
\hline $\begin{array}{l}\text { e) If the instructor and class discussed and agreed upon what would } \\
\text { constitute cheating in their course }\end{array}$ & 42.4 & 24.7 & 32.9 \\
\hline f) If the instructor knew my name & 42.5 & 30.0 & 27.5 \\
\hline g) If the instructor cared about my learning & 44.7 & 23.3 & 32.0 \\
\hline $\begin{array}{l}\text { h) If the instructor discussed the importance of ethical behavior at the } \\
\text { beginning of the term }\end{array}$ & 41.3 & 32.6 & 26.1 \\
\hline i) If the instructor encouraged students to be honest during the term & 43.7 & 24.9 & 31.4 \\
\hline $\begin{array}{l}\text { j) If the professor passed out multiple versions of the exam randomly to } \\
\text { students in the class }\end{array}$ & 47.3 & 22.6 & 30.1 \\
\hline k) If the instructor had additional proctors in the room during the exam & 48.8 & 22.0 & 29.2 \\
\hline l) If the instructor remained in and moved around the room during the exam & 47.0 & 21.5 & 31.5 \\
\hline m) If the instructor allowed us to work in groups on homework & 44.1 & 27.0 & 28.9 \\
\hline n) If the instructor wrote fair tests and homework & 40.9 & 25.8 & 33.3 \\
\hline $\begin{array}{l}\text { o) If the instructor passed out copies of old tests to everyone so we all had } \\
\text { the same study materials }\end{array}$ & 44.7 & 23.0 & 32.3 \\
\hline p) If the instructor provided a study guide or held a review before the exam & 44.5 & 24.1 & 31.4 \\
\hline q) If tests were open book or reference sheets were allowed & 43.0 & 21.5 & 35.5 \\
\hline v) If the instructor stressed how other people are hurt by my cheating & 41.3 & 34.7 & 23.9 \\
\hline w) If I felt the material in the course was important to my future career & 41.2 & 24.8 & 34.0 \\
\hline
\end{tabular}

Findings from the PACES-1 Project

Perhaps the most significant finding of this study is that frequency of student cheating depends on the student's definition. For example, Table 1 indicates that more students believe copying from another student on an exam is cheating compared to copying from another student on homework.

Peer-reviewed proceedings of the 2006 World Environmental and Water Resources Congress, Omaha, NB. 
This corresponds with a significantly higher frequency of students copying on homework than exams. Furthermore, the frequency of engagement in a behavior is higher for students who define an act as "unethical" as compared to those who define the act as "cheating" for every act except one (item k - "studying with other students for a test"). This suggests that a student's attitude toward the act has an important influence on their ultimate decision on whether to conduct the act.

Finally, students in this study were willing to engage in behaviors that they defined as wrong and which they perceived to carry risks of punishment. Furthermore, a student's definition of cheating directly affected their behavior. Together, these findings provide insight into a students' definition about what is or is not morally wrong and also their commitment to acting morally right. Thus, educators need to be concerned that students' have misguided moral principles - and that it may be our own educational system (and not some nebulous societal failure) that is causing the problem.

\section{Work Experiences Study (WES) Project}

It has been shown that students who admit to cheating in college are more likely to admit to dishonesty in the workplace (Sims, 1993; Nonis and Swift, 2001). Because of the importance of engineering decisions to the public welfare, this finding raises serious concerns about the apparent extension of unethical behavior from college into the workplace by engineering students. To further examine the connection between students' decisions to engage in or not engage in unethical behaviors in high school, in college, and in the workplace, the authors undertook the Work Experiences Study. Only some representative findings are presented here. Readers interested in a more detailed analysis can refer to several other manuscripts that have been published by the authors (Harding et al, 2003a; Harding et al, 2003b; Harding et al, 2004a; Harding et al, 2005).

The Work Experiences Study was designed to provide primarily qualitative data regarding students' decision making processes in instances in which they are tempted to violate workplace or school policies. It is a thirteen-item questionnaire consisting of three sections. The first section contains questions related to background, including the extent to which respondents worked in the past year and how frequently they cheated in high school. The second and third sections deal with decisions regarding ethical behavior in two settings: the college classroom and the workplace. In each setting, respondents are asked to consider a specific instance in which they had been tempted to behave unethically (i.e., cheat in the classroom or violate workplace policies), to describe any pressure(s) they felt to engage in the behavior and any hesitation(s) they felt to not engage in the behavior, and to describe the ultimate decision they made in this specific instance. Because the focus of this study is engineers in college and in the workplace, the sample used for this study includes undergraduate engineering students at two technical private universities where students either participate in an intensive cooperative education program or consist of non-traditional students who work in engineering settings. A total of 130 students enrolled at two technicallyoriented private universities responded to the survey. The sample consisted of second year $(7 \%)$, third year (42\%), fourth year (33\%) and fifth year (16\%) engineering undergraduate students. First year students were not included in the sample because of their lack of experience in either the academic or professional setting. Participants reported having full-time employment for an average of 6.78 months during the last academic year and working an average of 38.7 hours per week while employed full-time.

Peer-reviewed proceedings of the 2006 World Environmental and Water Resources Congress, Omaha, NB. 
Findings from the WES Project

Overall, 36.2\% of respondents decided to cheat in the situation they identified as being the one in which they were tempted to cheat, while $50.0 \%$ chose not to cheat (13.8\% provided no response). Likewise, of the respondents who indicated that they had been tempted to violate company policies in some way, $30.0 \%$ did violate the policies, $15.4 \%$ did not, and $10.8 \%$ followed some other course of action. A total of $43.8 \%$ of respondents chose not to provide a response to this question, for reasons unknown to the authors. There were three key findings from the results.

The first finding of this study is that past participation in unethical behavior can be a strong predictor of future participation in unethical behavior; i.e., students who report a prior tendency to cheat in high school are more likely to report cheating in a specific college situation and to report violating workplace policies. Of those who reported never cheating in high school, almost 70\% decided not to cheat in a specific instance in college and $50 \%$ decided not to violate workplace policies. On the other hand, less than $40 \%$ of those who reported frequently cheating in high school decided not to cheat in a specific instance in college and less than $10 \%$ decided not to violate workplace policies. This indicates that affecting an individual's behavior in one setting (i.e., college) could have a significant effect on the future behavior in another setting (i.e., workplace).

A second finding of the Work Experiences Study is that there are common factors that influence an individual's decision about whether to engage in or not engage in unethical behaviors in the classroom and in the workplace. Namely, common pressures in both settings include insufficient resources, importance of success, and projection of blame and common hesitations include moral obligation, conscience, risk of formal sanctions, and risk of detection. This finding indicates that there are distinct similarities in the decision-making process used by respondents in these two settings and is consistent with Nonis who studied 1051 business students and found that those who self-reported engagement in dishonest acts in college were more likely to report engaging in dishonest acts in the workplace (Nonis and Swift, 2001).

A third major finding of this work is that the context in which the decision to engage in or not engage in unethical behavior is made is very important. In the classroom, two possible contexts in which a student might consider cheating are exams and homework. Results of this study indicate that less than $15 \%$ of those who were tempted to cheat in an exam situation did, while more than $45 \%$ of those who were tempted to cheat on homework did. Similarly, in two workplace contexts, falsifying records and using company supplies improperly, decisions about whether to engage in or not engage in the behavior differed: less than $55 \%$ of those who were tempted did falsify records, while more than $70 \%$ of the respondents who were tempted to improperly use company supplies did.

\section{Concluding Thoughts}

The implications of academic dishonesty on professional ethical behavior are disturbingly apparent as evidenced by the work presented herein. In response, the authors continue to investigate, develop, and disseminate practical approaches for increasing academic integrity among engineering undergraduate students, which will in turn affect the integrity of engineers across the nation. Overall, the authors believe that the responsibility for promoting academic integrity lies with the entire college community, including students, academic institutions, and faculty as well as with engineering professionals who can provide positive role models for students and young engineers.

Peer-reviewed proceedings of the 2006 World Environmental and Water Resources Congress, Omaha, NB. 


\section{References}

ABC News. Cheaters Amok: A Crisis in America's Schools - How It's Done and Why It's Happening. Original report posted at the ABC News Web site: http://abcnews.go.com/sections/Primetime/US/cheating_040429-1.html.

Bowers, W.J. (1964). Student Dishonesty and Its Control in College. New York: Bureau of Applied Social Research, Columbia University.

Brown, B.S. (1996). A comparison of the academic ethics of graduate business, education and engineering students. College Student Journal, 30(September 1996), 294-301.

Brown, B.S. \& Emmett, D. (2001). Explaining the variations in the level of academic dishonesty in studies of college students: Some new evidence. College Student Journal, 35(4), 529-538.

Carpenter, D. D., Harding, T. S., Montgomery, S. M., \& Steneck, N. H. (2002a). P.A.C.E.S.--A study on academic integrity among engineering undergraduates (preliminary conclusions). Proceedings of the 2002 ASEE Annual Conference \& Exposition, Montréal, Quèbec, Canada.

Carpenter, D. D., Harding, T. S., Montgomery, S. M., Steneck, N. H., \& Dey, E. (2002b). Student perceptions of institutional and instructor based techniques for dealing with academic dishonesty. Proceedings of the $32^{\text {nd }}$ Frontiers in Education Conference, Boston, MA.

Cochran, J.K., Chamlin, M.B., Wood, P.B. and Sellers, C.S., "Shame, Embarrassment, and Formal Sanction Threats: Extending the deterrence/rational choice model to academic dishonesty,” Sociological Inquiry, Vol. 69, No. 1, 1999, pp. 91-105.

Fass, R.A. (1989). Cheating and Plagiarism. Ethics and Higher Education. W. W. May. New York, Macmillan: 170-184

Finelli, C. J., Harding, T. S., Carpenter, D. D., \& Passow, H. J. (2003). Students' perceptions of both the certainty and the deterrent effect of potential consequences of cheating. Proceedings of the 2003 ASEE Annual Conference and Exposition, Nashville, TN.

Harding, T.S., Carpenter, D.D., Finelli, C.J., \& Passow, H.J. (2004). Does academic dishonesty relate to unethical behavior in professional practice? An exploratory study. Science and Engineering Ethics, 10, 311-324.

Harding, T.S., Carpenter, D.D., Finelli, C.J., \& Mayhew, M.J. (2005). Cheating in college and the workplace: An examination of engineering undergraduates' ethical behavior. Proceedings of the ASEE Annual Conference and Exposition, Portland, OR.

Harding, T. S., Carpenter, D. D., Finelli, C. J., \& Passow, H. J. (2003a). An examination of the relationship between academic dishonesty and professional behavior. Proceedings of the $33^{\text {rd }}$ Annual Frontiers in Education Conference, Boulder, CO.

Harding, T. S., Carpenter, D. D., Finelli, C. J., \& Passow, H. J. (2003b). The relationship between academic dishonesty and ethical behavior in engineering practice. Proceeding of the 2003 Ethics and Social Responsibility in Engineering and Technology Conference, New Orleans, LA.

Harding, T. S., Carpenter, D. D., Montgomery, S. M., \& Steneck, N. H. (2001). The current state of research on academic dishonesty among engineering students. Proceedings of the $31^{\text {st }}$ Frontiers in Education Conference, Reno, $\mathrm{NV}$.

Peer-reviewed proceedings of the 2006 World Environmental and Water Resources Congress, Omaha, NB. 
Hilbert, G.A. (1985). "Involvement of Nursing Students in Unethical Classroom and Clinical Behaviors." Journal of Professional Nursing 1: 230-234.

McCabe, D.L. \& Trevino L.K. (1997). Individual and contextual influences on academic dishonesty: A multicampus investigation. Research in Higher Education, 38(3), 379-396.

McCabe, D.L. (1997). Classroom cheating among natural science and engineering majors. Science and Engineering Ethics, 3, 433-445.

McCabe, D.L. \& Drinan, P. (1999). Toward a culture of academic integrity. Chronicle of Higher Education, 46(8), B7.

Nonis, S. and C.O. Swift (2001). "An Examination of the Relationship Between Academic Dishonesty and Workplace Dishonesty: A Multicampus Investigation.” Journal of Education for Business: 69-77.

Ogilby, S.M. (1995). The ethics of academic behavior: Will it affect professional behavior? Journal of Education for Business, 71(2), 92-96.

Passow, H.J., Mayhew, M.J., Finelli, C.J., Carpenter, D.D., \& Harding, T.S. (2005). Factors influencing engineering students' decisions to cheat by type of assignment. Proceedings of the 2005 Annual Meeting of the American Educational Research Association Montréal, Quèbec, Canada.

Passow, H.J., Mayhew, M.J., Finelli, C.J., Harding, T.S., \& Carpenter, D.D. (2006). Factors influencing engineering students' decisions to cheat by type of assessment. Research in Higher Education. Vol. 47, no. 5.

Sims, R.L. (1993). The relationship between academic dishonesty and unethical business practices. Journal of Education for Business, 68(4), 207-211.

Spiller, M.S.\& Crown, D.F. (1995). Changes over time in academic dishonesty and unethical business practices. Journal of Education for Business, 68(4), 207-211.

Todd-Mancillas, W.R. (1987). Academic dishonesty among communication students and professionals: Some consequences and what might be done about them. Proceedings of the Annual Meeting of the Speech Communication Association.

Whitley, B.E. and P. Keith-Spiegel (2002). Academic Dishonesty: An Educator's Guide. Lawrence Erlbaum Associates Mahwah, NJ

Peer-reviewed proceedings of the 2006 World Environmental and Water Resources Congress, Omaha, NB. 